2016-09

\title{
Embedding sustainability literacy in the legal curriculum: reflections on the Plymouth model
}

\section{Lowther, Jason}

http://hdl.handle.net/10026.1/9704

\subsection{0/03069400.2016.1240919}

The Law Teacher

Informa UK Limited

All content in PEARL is protected by copyright law. Author manuscripts are made available in accordance with publisher policies. Please cite only the published version using the details provided on the item record or document. In the absence of an open licence (e.g. Creative Commons), permissions for further reuse of content should be sought from the publisher or author. 
"This is the author's accepted manuscript. The final published version of this work (the version of record) is published by Routledge in The Law Teacher, December 2016, Journal available at: http://dx.doi.org/10.1080/03069400.2016.1240919. This work is made available in accordance with the publisher's policies. Please refer to any applicable terms of use of the publisher."

\title{
Embedding sustainability literacy in the legal curriculum: reflections on the Plymouth model
}

Jason Lowther, a and Joanne Sellick, b

a. Associate Professor in Law, Plymouth Law School, Plymouth University, Plymouth,UK and Corresponding author. Email: jason.lowther@plymouth.ac.uk;

b. Associate Dean for Teaching and Learning, Faculty of Business and EU Law Module Leader, Plymouth Law School, Plymouth University, Plymouth, UK

\begin{abstract}
Plymouth Law School was an early adopter of the Education for Sustainable Development (ESD) credo, and embarked on a series of measures designed to embed sustainability in its law curricula, which have since been refined and developed. This article is intended to supplement the theoretical ESD discourse by offering a reflective assessment of our practice and experiences in embedding sustainability by utilising the Foundation subjects of Legal Systems and Skills and European Union Law. In the case of the latter, sustainability is embedded as a delivery vehicle through which students are encouraged to critically explore the practical operation and efficacy of EU enforcement methods, principally from the perspective of EU water policy and law. This builds upon engagement and exposure at level 4 and prior learning in the level 5 EU Law module itself. Importantly it also serves to cement the association of sustainability with legal imperatives and allows us to apply a different lens to sometimes abstract judicial creations such as direct effect and state liability within a tangible setting. Developing autonomy is an additional significant learning outcome of the programme. The approach we have developed is based on combining these two imperatives.
\end{abstract}

\section{Introduction}

Plymouth Law School embraced the possibility of embedding sustainability into its curriculum1 relatively early. This was inspired in part by institutional support and the pioneering work of academics such as Professors Stephen Sterling and David Selby who led the University's Centre for Sustainable Futures, 2 a centre for excellence in teaching and learning, and in part by the interests of a small number of the School's 
academic staff. Very briefly, the Law School opted for a pervasive approach, seeking to infuse sustainability throughout the programme, rather than adopting a specific sustainability "module". 3

There were a number of reasons for this, including the space required in an already packed programme to add another core module. Discussions between those interested in Education for Sustainable Development (ESD) further identified the significance of "sustainability values" 4 as being reflected in a range of legal subject areas and thus a pervasive approach, it was felt, could produce a contextualised syllabus based on those values. The result is an embedding of sustainability as a feature across all three levels of the undergraduate Law curricula. It is also a feature of interdisciplinary teaching delivered by the Law School on environmental science programmes at undergraduate and postgraduate levels, which seeks to locate the relationship between values, policy and the law, although for considerations of space these are not expanded upon here. 5

Our students are first introduced to sustainability as a key value at level 4 in the Legal Systems and Skills module. Here, sustainability provides a vehicle for introducing the institutions and basic structure of Public International Law (itself introduced some time ago to provide early exposure to a more internationalised programme). Focus is placed on the United Nations Conference on Environment and Development (UNCED), its outputs and successor mechanisms. Scaffolded learning takes place at level 5, where the module EU Law significantly expands on the fit with sustainability and law. Given that the Union sees sustainable development as a key competence that is pervasive within its "programme" it seemed logical to adopt such an approach. The aim is incrementally to build appreciation of the conceptual basis and then to place this in an applied setting: substantive and procedural EU law provides that applied context.

Because both these modules cover foundations of legal knowledge and thus are a requirement for our "qualifying" law degrees we are able to maximise exposure without compromising core accrediting body requirements. It has been noted by Reid and Ali that there is little if any overt value placed upon finding space for sustainable development in the traditional legal curriculum by the professional bodies, 6 although, perhaps ironically, law firms themselves are often happy to espouse their sustainability credentials. As our students progress to level 6 there are further opportunities to study aspects of sustainable development more systemically in elective modules. In the case of two of these, environmental and immigration law, EU Law offers a "launch pad" by including both sustainability as discussed below, and EU citizenship and free movement of people within its syllabus.

In this article we will outline the EU Law module and the teaching and learning methodology. We will then go on to link this to the EU's sustainability imperatives and explain the use of a specific resource, water, before concluding with a series of reflections on our experiences to date. Having exited the UN's Decade of Education 
for Sustainable Development, 7 it seemed an appropriate point to reflect on our approaches.

\section{The EU Law module}

The fulcrum of the development of our students' competency with sustainability concepts is a level 5, second year, 20-credit EU Law module, until now delivered over a traditional academic year.8 After an introduction to reinforce key knowledge from level 4 (primarily institution based), the syllabus is constructed of three distinct parts. The first undertakes an in-depth exploration of the various means of enforcing EU law. The second, developed in 2010, came about as a result of the module team's decision to introduce sustainability. It occurs at this stage of the syllabus to provide a means of ensuring both the cementing of sustainability literacy and a practical vehicle for comprehending the often arcane EU enforcement processes, an aspect of the syllabus students had traditionally found difficult to appreciate. There is a clear synergy here: students of EU law gain a deeper and practical understanding of how the law is enforced; and in doing so their competences are augmented though the contextual linkage to acritical EU policy imperative. Thus the methods by which laws are enforced against member states for failure to fulfil their EU law obligations are an intrinsic part of the design for learning from this resource. By fusing it with the notion of sustainability, the approach permits the user to appreciate in a practical way how failures in implementation are dealt with, to perceive potential outcomes, including consequences/sanctions for the member state; and permits the potential for an evaluative application of the extent to which member states' practices are aligned with the sustainability imperative.

\section{The learning resource: aims and objectives}

The material has been developed into an interactive resource: an "e-workbook", which is provided via the Digital Learning Environment pages for the module. Within the substantive content of the module, the e-workbook serves two principal and complementary functions. First it seeks to provide the opportunity to contextualise EU law and policy: to appreciate the rationale behind the law and observe how legal obligations arise from policy imperatives. Additional focus is placed on the consideration of concrete examples of how EU law is enforced. The basis is to assist in the consolidation of the knowledge acquired up to that point in a tangible and connected "real-life" setting.

The second function is to map learning about the policy-law relationship (and the concomitant enforcement efforts which aim to make this a reality) onto the sustainable development imperative which the EU has adopted as a key responsibility and driver for its law across all areas of its competence. Ancillary, 
practical, benefits are skills based. First, there is the augmentation of research and information retrieval skills, in this case from key EU and other official sources. Second, the learning resource encourages autonomous learning, discussed further below. Thus we articulate the key learning objectives for the e-workbook to our students in the following terms:

[a]fter completion of the tasks, you should be able to:

- critically assess the effectiveness of the methods of enforcing EU law;

- demonstrate familiarity with the EU's Sustainable Development policy and the role of law in achieving it;

- apply the above knowledge in the context of water quality;

- locate and analyse examples of the enforcement of EU law;

- work autonomously with limited direction; and

- navigate the key EU, and other, databases to locate and access primary and secondary legal materials.

In essence, the sustainability focus is explicit - the fact that there is a symbiotic relationship with some wider skills development provides an added benefit with students becoming familiar with a broader range of instruments than those which a purely strait-jacketed pedagogical approach would permit. Examples here include synthesis of institutional documents and questions raised on issues within the European Parliament to take the appreciation of the subject matter beyond just rule and application. Obviously, though, the mainstay is the law, and exercises to identify barriers to its effectiveness (for example as identified by the European Commission in the context of sustainable development9) permit more comprehensive investigation and assist with critical thinking.

\section{The learning resource: priming, structure and content}

The e-workbook offers an overall narrative, but the heart of it is the collation and hyper-linkage to a wide variety of sources, underpinned by a series of scaffolded, practical tasks requiring students to locate, extract and interpret information, as well as to make qualitative assessments. As the tasks are completed, the workbook becomes a student-owned resource in itself so as to facilitate appreciation of the subject matter and ultimately to prepare for the summative assessment. In an initial, plenary large group session, students are offered a contextualised introduction to sustainability and expectations associated with studying the e-workbook. The syllabus schedule is then specifically designed to offer time for its autonomous study. 
To date this has been over a three-week period prior to the end of term 1 followed by the Christmas vacation period.

Experience indicates that students tackle the e-workbook in a variety of ways - some completing it in a "one-stop" approach, asking for feedback in a matter of days. Others take a more deliberative approach and pace their study whilst, as might be expected, others take much longer to complete it. In our opinion this is one of the advantages of the workbook - its flexibility encourages students to manage their time in a way that best suits them in light of their other learning and commitments. Having reflected on this experience, we added to the e-workbook's introductory material a study-log designed specifically to assist students in managing their independent study, which in turn we have since found being used as evidence in personal development planning.

The e-workbook begins with a brief introduction to sustainable development tin the $\mathrm{EU}$, designed to recap and build upon the knowledge gained about sustainability more generally at level 4 . It moves on to consider the extent to which it is now a determining feature of EU legal and policy developments. The more substantive content is arranged into three discrete but incremental sections:

- Part A: examines more fully the enforcement mechanisms available to the Commission via direct action set out in Articles 258-260 of the Treaty on the Functioning of the European Union (TFEU) in the context of sustainable development;

- Part B: examines direct effect and state liability in the context of legal materials and judgments, both national and from the Court of Justice of the European Union (CJEU), reflecting sustainable development discourses; and

- Part C: contains exercises exploring all of the above in the context of promoting cleaner bathing water in the EU.

All three parts feature a singular thread - consideration of EU water law in one or other of its guises. Parts A and B more overtly link enforcement to legally effective sustainability; Part $C$ requires greater synthesis, and solutions thinking to a specific $\mathrm{EU}$ issue of water quality. Below is an explanation of the rationale for the selection of water policy and law as this singular thread. 


\section{The learning resource: assessment}

In its first iteration, summative assessment of knowledge and understanding associated with the e-workbook was limited to an optional question on an examination comprised of eight questions, with candidates required to select any four to answer. No candidate attempted the question, prompting discussion and reflection on whether the significance of sustainability literacy in both the module and the programme was sufficient to justify a change of approach.10 Our conclusion was that if we claim sustainability literacy as an attribute of our graduates we were obligated to encourage, support and nurture this quality in a more structured learning environment. Substantive knowledge and understanding from study of the workbook are still assessed in the end of module examination, but now via a compulsory section comprised of objective and short answer questions representing $25 \%$ of the overall total marks for the exam. Students are supported in their learning throughout the module with formative assessment opportunities and a tutor "open door" query and feedback policy; at any point, from the first introduction to thee-workbook until the very end of the module's delivery, students are positively encouraged to forward their completed tasks, or the entire e-workbook, for comment and feedback.

\section{Sustainability and the fit with EU law}

Sustainable development is central to the EU mission, presented as its "overarching long-term goal".11 In that regard, a Sustainable Development Strategy, revised in 2006 and reviewed in 2009 seeks to balance economic growth, social cohesion and environmental protection within its long-term vision. The Strategy explicitly reflects the traditional Brundtland definition: "Sustainable development means that the needs of the present generation should be met without compromising the ability of future generations to meet their ownneeds", 12 and continues that as an objective it is one that governs all of the Union's policies and activities. There are some big ticket items here: climate change and energy policy being perhaps the most obvious, and more recently the adoption of measures in relation to a coherent maritime policy.13 Where the EU differs in a fundamental way from most other international bodies is that it has the legal mechanisms to give effect to its expressions of policy in legislative form. In that sense it provides us with a useful basis from which to demonstrate to our students the centrality of law to furthering core sustainability values. The Constitutional Treaties of the EU task the organisation to promote sustainable development, whether within the Union itself or via its relationships with the world beyond its borders. Article 3 of the Treaty on European Union (TEU) provides the basis, stating (emphasis added):

... [Art. 3(3)] The Union shall establish an internal market. It shall work for the sustainable development of Europe based on balanced economic growth...social progress, and a high level of protection and improvement of 
the quality of the environment ... and shall ensure that Europe's cultural heritage is safeguarded and enhanced ...

...[Art. 3(5)] In its relations with the wider world, the Union shall...contribute to peace, security, the sustainable development of the Earth, solidarity and mutual respect among peoples, free and fair trade, eradication of poverty and the protection of human rights ...

A better indication of how this is to be achieved is provided in Article 11 of the TFEU which states that:

Environmental protection requirements must be integrated into the definition and implementation of the Union policies and activities, in particular with a view to promoting sustainable development.

Article 11 is a useful indicator as to the centrality of the environmental dimension to sustainability and the imposition of certain obligations for the EU and the member states. The link is very much kept to the physical environment.

Krämer notes that there are some 28 policy areas where environmental considerations would be in play, including (with relevance to the workbook)public health, employment and social affairs, human rights and maritime affairs and fisheries.14 To take two specific examples in the workbook, there are exercises relating to bathing water, discussed further below, which engage an understanding and appreciation of information rights and their contribution to environmental regulation and thus sustainable development; and other tasks related to exploring issues which consider water quality and health.15Krämer also observes that there is a substantial imperative within Article 11 asit identifies that the implementation of the policy areas will apply to "...legislative acts, executive and implementing decisions and other measures which the EU institutions, agencies, bodies and offices might take":16 this is the basis of our thinking in the design of the structured exercises within the workbook - i.e. to require our students to critically assess the extent to which this takes place.

At least at face value, having what look like such unequivocal statements of aspiration and obligation - particularly by reference to environmental protection reinforces the purpose of including sustainability as a component of the EU syllabus. It really is a "thing" 17 and such an overt linkage makes the task of engaging the students' interest a little more straightforward. Obviously good water quality is essential to all aspects of sustainable development: economic, social and environmental, and the choice of this as a basis for engagement is discussed in the next section. Consequently there has been a plethora of regulatory measures with increased sustainability focus. Such regulatory measures mean that there will inevitably be a requirement for enforcement, enabling students to engage with the process and teleological reasoning of the CJEU in promoting environmental protection and ultimately contributing to more sustainable practices. 


\section{Water as the linking factor}

Selecting the right basis of the investigation is, as touched upon above, crucial to an interesting and relevant learning experience. An approach which is too broad or esoteric, or perceived as introducing material from another subject area, risks losing or alienating some of the cohort. Conversely, if it is too narrow there is a risk that the experience becomes mechanical, and does not produce creative and critical thinking. The stated purpose of the approach we have adopted is to encourage reflection on the role of law in promoting or achieving sustainability. Additionally this must also be something that is capable of providing a research challenge whilst retaining a degree of familiarity. The initial attempt was unquestionably too "big", and so rather than a focus on the European environment per se we opted for something more discrete, with an explicit sustainability dimension, and which is well resourced in terms of historic and evolving policy, regulatory mechanisms and enforcement actions. We opted for water quality for the following reasons - first, its centrality to life; second, it offers numerous "real-life" regulatory and judicial examples; third, it permits a tangible local study; and finally, it acts as a bridge in the development of sustainability literacy within the curricula.

As a shared resource vital for survival, water is familiar, easily conceptualised, and something which is central to sustainability discourses. It is are source under considerable and differential pressure within the territory of the EU18 - something which UK-based (law) students are potentially unaware of, at least in any detailed way, unless perhaps they elect to study environmental law. A focus on access to water and its quality for certain uses permits consideration of value, availability and allocation issues, as well as human and environmental impacts, socio-economic and cultural implications. In addition ,in an EU context, it provides a very clear illustration of the development of values-based policy and general provisions of law. These broader concerns are then able to be funnelled to become more narrowly focused, enabling the learner to chart and appreciate the role that law plays in matching purpose to outcome.

Inevitable regulatory transgressions occur, which require that the CJEU interprets and applies the law in response to Commission enforcement actions under Article 258 TFEU. The majority of cases are direct actions in relation to the failure to implement a substantive legal requirement. There are, however, additionally issues of potential direct effect and state liability as well as the regimes for lump sums and penalty payments provided in Article 260 TFEU. A series of water-focused cases helps to contextualise this.19 Thus, e-workbook exercises relate to the parties' submissions and the Court's reasoning helping to bring the importance of the contested measures to the fore. The purpose is to reflect, through autonomous investigation, the twin aims of reinforcing prior learning on the enforcement processes in the context of sustainability concerns when mapped on to aspects of EU water law and policy. With the knowledge that the majority of our students are from the South West, focus on bathing water quality, particularly in the region, 
provides a tangible jump-off point to contextualise transformative thinking in relation to how regulatory systems operate to create meaningful obligations which contain sustainability imperatives. The peninsula is famed for its coastline and leisure uses of the sea are of central importance in the socio-economic fabric of the region. Through research exercises based on the Urban Waste Water Treatment and Bathing Water Directives and case law that stems from them more generally, students can chart improvements in water quality and consider the obstacles which have been encountered and the means by which these have been overcome.

The focus on water also provides a bridge between curricula levels so far as the development of sustainability literacy is concerned. At level 4 one of the exercises requires an appreciation of the Millennium Development Goals,20and specifically Goal 7 which has as its focus environmental sustainability. A key component of this Goal was contained in Target 7.C: "Halve, by 2015, the proportion of the population without sustainable access to safe drinking water and basic sanitation". That this target has, it is claimed, been met five years ahead of schedule is laudable, although the United Nations Development Programme (UNDP) reflects that there is still work to be done in that "[I]n2012, 748 million people remained without access to an improved source of drinking water"; and that "[D]espite progress, 2.4 billion in developing countries still lack access to improved sanitation facilities".21Clearly the EU focus is somewhat different compared to the exclusively anthropocentric rationale behind the Millennium Development Goals, although the basic concern to improve water quality is a shared constant. Water is also a key area of focus in the EU's Sustainable DevelopmentStrategy.22 Appreciating how law provides concrete obligations which reflect sustainability in terms of both aspiration and impact - utility and effect if you like - is part of the conceptual challenge we hope to showcase and set for our students. The quality of Europe's aquatic environment has improved steadily following consistent EU legislative intervention.23This has dovetailed with an enhanced appreciation of the need to manage Europe's water resources, particularly in respect of certain abstractions and inputs which are capable of affecting the sustainable development of the resource. The EU's policy and legal approach have been to regulate for the whole of the water cycle, including relating to specific uses of water(e.g. drinking, fisheries, bathing, etc.). It has also considered the regulation of the principal pollutants which are able to enter and contaminate water sources, such as from agriculture, industry and from sewage (e.g. urban waste water).24 Provision of sanitary means of disposing of waste water has quite fundamental sustainable development characteristics implicit including, so far as the traditional triumvirate is concerned: 25

- Social - (public health, leisure - angling, boating, bathing, surfing)

- Economic - (infrastructure development, tourism, fisheries, poverty)

- Environmental - (public health, pollution control, conservation of species and habitat) 
The majority of measures, and all of those which are the focus of the workbook, are Directive-driven and thus member states are required to take the lead in delivering the intended outcomes. Those outcomes are driven by both quality standards and sustainability indicators. The range and complexity of the measures required, and in some cases the infrastructural and linked economic costs consequent upon the obligations have, perhaps inevitably, resulted in a considerable corpus of law relating to enforcement. All principal methods of enforcement have been used by the Commission at one time or another and Treaty changes along the way, reflecting for example the increased prominence of sustainability in the EU canon, provide both coherence and context for the learning experience. In this respect a deeper appreciation of policy drivers and the regulatory and enforcement landscape is encouraged and facilitated. An ancillary benefit is the potential for discussion around, for example, the generally significant levels of payments required of states under the Article 260 TFEU (ex 228) procedure and possible imbalance between socioeconomic and environmental outcomes. 26

\section{Reflection, refinement and feedback}

Initially, the primary difficulty was achieving a balance, whereby the substantive EU law syllabus requirement was delivered and the sustainability dimension adequately reflected. As mentioned above, on reflection our first attempt was skewed too much towards teaching what, in effect, was EU environmental law. While it very much reflected the interests of the module team, and tackled sustainability concepts headon, it proved conceptually difficult to some students, who, frankly, had little interest in, for example, wider notions of the EU's environmental competences. Essentially this provided a barrier to the objective of engaging sustainability thinking and developing literacy and prompted a reassessment. Following a year when the workbook was suspended due to staff resourcing issues, it was relaunched three years ago with a narrower and more defined focus, and has been subject to more minor refinements since. As discussed, the defined focus is to theme the e-workbook on the approachable, yet contentious area of water quality. This has permitted the sustainability dimension to feature prominently, but without being overshadowed or seen as only an "environmental" - despite its centrality - concern. Focus on a narrower aspect of one environmental issue has also permitted a deeper learning experience where sustainability learning across all of its facets appears intuitive, despite its multidimensional qualities.

We have sought feedback on the workbook from both the students and our external examiners as critical friends. In both circumstances the feedback, insofar as it has been explicitly given, has been positive. So far as the learners are concerned there has been a general feeling - garnered mainly though comments made to the module team and in response to formative feedback - that the workbook has added an unexpected dimension to their appreciation of EU law: "I enjoyed the opportunity to 
look at something completely different ...". Those that particularly enjoy this dimension inform us that they go on to deliberately elect to study environmental law at level 6, and/or to base their dissertation in this area. The fact that the e-workbook is primarily a research exercise not based on a "chapter in the textbook" has also been appreciated. This is perhaps not as surprising as it might first appear, given that there is a deliberate programme strategy to train students at level 4 so they are familiar with locating, reading and analysing primary and secondary materials. The success of this is well evidenced by our students at level 5 being comfortable with and capable of learning without reliance on a "core text". Many of the students appear to equally enjoy managing their autonomous learning: "I appreciated the range of materials and the way the workbook permitted me to learn at my own pace" and to value the level of support offered to underpin this: "Great formative feedback helped me understand how to get more from the exercises".

What has perhaps been most striking is the fact that there has not been one explicitly negative comment in module evaluations (save for one speculating that the examination would be more difficult as a result of introducing the compulsory section on the e-workbook. This has never been repeated, and module results do not generally support this, although as to be expected performance covers the full range and is reflective of motivation and engagement27). Given that the student body is often considered more demanding and perhaps quicker to voice its disapproval in the higher fees landscape, we consider this as positive! Research by Drayson et al. indicates a very strong expectation on the part of students that sustainable development should be a feature of their learning,28 and this may to a certain extent explain the apparent positivity our students express.

Input and feedback from the external examiners who have overseen this module have been consistently positive, giving us the confidence to continue and develop both the mode of delivery and assessment: "[s]ustainability as across cutting theme for the LL.B works well";29 "[t]he sustainable development theme is very well incorporated into the module and enhances student autonomous learning. Student feedback is highly complementary about the standard of teaching".30 Of note is reference to our approach having a positive motivational and engagement effect: "[t]here was evidence of a high level of student engagement with this module which is impressive, as students across the HE sector generally tend to be resistant to EU law".31What we have learned from the use of the method is that the e-workbook should remain an organic and reflexive document. We recognise that there is the potential to move away from the water aspect; however we believe it provides a very clear "global to local" example where law is arguably effective in contributing to positive change, or at least where its effectiveness may be located in a setting which enables regional focus and requires continual reflection. 


\section{Conclusions and next steps}

Over the five years of its use, the e-workbook has evolved, iteratively, into a valuable resource. Following fine-tuning over this period we are now confident that our approach and the resources developed are effective. However, we continue to reflect and are currently exploring transforming the e-workbook into an e-portfolio delivered through Pebblepad. With direct assessment of the extent to which sustainability concepts are assimilated and understood, the module team has some confidence that our students have a reasonable appreciation of sustainability, and have augmented their skills as autonomous learners as they enter level 6 . So far we have anecdotal and experiential evidence of the extent to which the approach we have taken contributes to creating more sustainability literate law graduates(examples of this would include dissertation choice, the selection of environmental law at level 6 as an elective and performance on modules where there is a greater emphasis on autonomous research tasks). We believe this is a result of the very deliberate way the e-workbook presents sustainability as a "given" in the same way that it is declared as such within the EU project. It is something pervasive, holistic and not something to be studied once and forgotten, and our students appear to have embraced this message. Further research, seeking to test our perceptions of progress and to establish the extent of this literacy is the next logical step. In that connection, gaining a more complete understanding of the appreciation of sustainability amongst our students and ascertaining the extent of its significance to them in their legal thinking are the next challenges. We have certain data based on our experiences to date but consider that a more systematic evaluation of the position will enable future curriculum innovation. While our students are undoubtedly exposed to sustainability thinking, it is incumbent on us as legal educators to reflect upon our practice and refine what we do. Perhaps the next decade is one of consolidation? 


\section{ENDNOTES}

1. In the context of this discussion there are three LLB QLD programmes. More recently Education for Sustainable Development (ESD) was extended to the Graduate Diploma in Law programme in a similar way to that presented in this article.

2. Details of current projects, etc. are available at https://www.plymouth.ac.uk/youruniversity/sustainability (accessed October 2016).

3. Interested readers will find the background and rationale, etc. in T. Varnava, J. Lowther and $\mathrm{S}$.

Payne, "Sustainability, Is It Legal? The Benefits and Challenges of Introducing Sustainability into the

Law Curriculum", in P. Jones, D. Selby and S. Sterling (eds), Sustainability Education:

Perspectives and Practice Across Higher Education (London, Earthscan, 2010), pp. 133-154.

4. Ibid. A number of these values are discussed and applied in the context of law in work undertaken

by H. Brayne and T. Varnava for the UKCLE; see also S. Sterling, "The Future Fit

Framework: An Introductory Guide to Teaching and Learning for Sustainability in HE” (York, HEA, 2012).

5. A contemporary and full discussion of related issues can be found in J. Holder, "Identifying Points

of Contact Between Legal and Environmental Education" (2014) 40(4) Journal of Law and Society

541-569.

6. C. Reid and N. Ali, ESD and the Professional Curriculum (University of Dundee, HEA, 2011).

7. UNESCO, detail available at http://unesdoc.unesco.org/images/0014/001416/141629e.pdf (accessed October 2016).

8. For 2015/2016 and introduction of Plymouth's Curriculum Enrichment Project, the module will be

delivered over the second semester. Total contact time will remain effectively the same whilst

the module is of a shorter duration, students will be studying only two other modules.

9. Progress Report on the Sustainable Development Strategy 2007, COM(2007) 642 final, Brussels.

10. Additional reflection on the evolution of the resource is discussed below.

11. Communication from the Commission - Mainstreaming sustainable development into EU policies

(Brussels, European Commission, 2009), $\operatorname{COM(2009)} 400$ final. Available at http://eurlex.europa.eu/legal-content/EN/TXT/PDF/?uri=CELEX:52009DC0400\&from=EN (accessed June 2015).

12. Council of the European Union, Renewed Sustainable Development Strategy, 10117/06 (Brussels, 
2006), paragraph 1. Available from

http://register.consilium.europa.eu/pdf/en/06/st10/st10117.en06.pdf (the first five pages give a good account).

13. Components of which include Directive 2008/56/EC establishing a framework for community action in the field of marine environmental policy (Marine Strategy Framework Directive) (OJ 2008

L 164/19); and Directive 2014/89/EU establishing a framework for maritime spatial planning (OJ 2014 L 257/135) amongst others.

14. L. Krämer, "Giving a Voice to the Environment by Challenging the Practice of Integrating Environmental Requirements into Other EU Policies", in S. Kingston (ed.), European Perspectives on

Environmental Law and Governance (Abingdon, Routledge, 2013), pp. 83-101.

15. Students are required to access and make use of official information sources from the EU, UK government and appreciate the use made by, for example, NGOs such as Surfers Against Sewage in their role as an environmental watchdog, and promoting coastal water quality.

16. Krämer, supra n. 14, p. 89.

17. With due thanks to N. Graham, "This Is Not a Thing: Land, Sustainability and Legal Education" (2014) 26 Journal of Environmental Law 395-422, for the device.

18. Discussed, for example, in J. Sellick, "The State of Europe's Water Resources" (2008) 19 Water Law 185-193, and used in the e-workbook as a scene-setting reading task.

19. For example, but not limited to, consideration of cases such as: Case C-390/07 Commission v UK

[2009] ECR I-214 (Waste Water - enforcement action), C-395/13 Commission v Belgium [2014] ECR 0 (enforcement action, argued (rejected) defence); C-374/11 Commission $v$ Ireland [2012] ECR 0 (Art.260); Bowden v South West Water Services [1999] Env. LR 438 (discussion of potential for state liability), etc.

20. Available at http://www.un.org/millenniumgoals/. 2015 is a significant milestone year, and the

Millennium Development Goals Report provides an assessment of progress towards the goals and notes the development of post-2015 Development Goals,

http://www.un.org/millenniumgoals/2015 MDG Report/pdf/MDG\%202015\%20rev\%20(July \%201).pdf (accessed October 2016).

21. Target 7.C, available at http://www.un.org/millenniumgoals/environ.shtml (accessed October

2016).

22. There are four focus areas identified as long-term goals (shift to a low-carbon and lowinput economy; protection of biodiversity, air, water and other natural resources; strengthening the social dimension; and the international responsibility). See also, COM(2010), 2020 EUROPE 2020, A European strategy for smart, sustainable and inclusive growth. Available at http://ec.europa.eu/eu2020/pdf/COMPLET\%20EN\%20BARROSO\%20\%20\%20007\%20\%20Europe\%202020\%20-\%20EN\%20version.pdf (accessed June 2015). 
23. The EU's water information resources can be accessed from the Commission's webpages at http://ec.europa.eu/environment/water/index en.htm , and specifically in relation to bathing water the most recent reports detailing quality, see European Environment Agency, "European Bathing Water Quality in 2014", EEA Report No. 1/2015 (2015). Available at http://www.eea.europa.eu/publications/european-bathing-water-qualityin-2014/download (accessed June 2015).

24. See for example Directive 91/271/EEC on Urban Waste Water Treatment (OJ 1991, L 135/40) as amended; Directive 2000/60/EC establishing a framework for the Community action in the field of water policy (OJ 2000, L 327/1).

25. Cultural use, particularly of the sea, is also included in a broader conception of sustainable development. In terms of cultural sustainability, see for example The Hangzhou Declaration Placing Culture at the Heart of Sustainable Development Policies, Adopted in Hangzhou, People's Republic of China 2013, UNESCO.

http://www.unesco.org/new/fileadmin/MULTIMEDIA/HQ/CLT/images/FinalHangzhouDeclarat ion20130517.pdf (accessed June 2015).

26. Case C-374/11 Commission v Ireland, CJEU 19 December 2012, for example was related to the balancing of the failure to protect groundwater through the Urban Waste Water Treatment Directive, and the fact that Ireland's economy was weakened as a result of the global financial crisis.

27. Module results have gradually improved over the past three years, particularly in terms of those achieving a 2:1 or above.

28. R. Drayson, E. Bone, J. Agombar and S. Kemp, Student Attitudes Towards and Skills for Sustainable Development (HEA, 2014). The executive summary is available at https://www.heacademy.ac.uk/system/files/executive-summary-students.pdf (accessed October 2016).

29. EE Subject Assessment Panel Report 2011-12.

30. EE Subject Assessment Panel Report 2012-13.

31. EE Subject Assessment Panel Report 2011-12. 